\title{
UM CORPO TODO SEU: JUDITH TEIXEIRA, FLORBELA ESPANCA E MARIA TERESA HORTA'
}

\section{A BODY OF YOUR OWN: JUDITH TEIXEIRA, FLORBELA ESPANCA AND MARIA TERESA HORTA}

\author{
Isa Vitória Severino² \\ Jonas Leite ${ }^{3}$
}

\begin{abstract}
RESUMO: No âmbito da nossa participação, pretendemos, numa perspectiva diacrónica, analisar alguns poemas de três escritoras portuguesas - Judith Teixeira (1880-1958), Florbela Espanca (1894-1930) e Maria Teresa Horta (1937). A nossa escolha recai sobre as três mulheres poetas quer pelo papel que assumiram na sociedade portuguesa, quer pelos temas que emergem da sua poesia, exaltando o corpo e, através dele, a liberdade de expressão e a voz femininas. Assim, num diálogo intertextual e a duas vozes, propomos (re)visitar poemas das autoras em questão que melhor ilustram a temática em análise.
\end{abstract}

PALAVRAS-CHAVE: Poesia. Corpo. Transgressão. Judith Teixeira. Florbela Espanca. Maria Teresa Horta.

ABSTRACT: In the scope of our participation, we intend, in a diachronic perspective, to analyze some poems by three Portuguese writers - Judith Teixeira (1880-1958), Florbela Espanca (1894-1930) and Maria Teresa Horta (1937-). Our choice falls on the three women poets, either because of the role they assumed in Portuguese society, or because of the themes that emerge from their poetry, exalting the body and, through it, freedom of expression and the female voice. Thus, in an intertextual dialogue with two voices, we propose to (re) visit poems by the authors in question that best illustrate the theme under analysis. KEYWORDS: Poetry. Body. Transgression. Judith Teixeira. Florbela Espanca. Maria Teresa Horta.

\footnotetext{
${ }^{1}$ Artigo recebido em 10 de março e aceito em 20 de abril de 2021.

2 Doutora em Literatura; Instituto Politécnico da Guarda-Portugal. E-mail: isaseverino@ipg.pt. ORCID: https://orcid.org/0000-0001-5452-8853.

${ }^{3}$ Doutor em Literatura e Interculturalidade; Universidade Federal de Pernambuco; jonasleite@hotmail.com; ORCID: https://orcid.org/0000-0001-9001-7786.
} 


\section{Introduçầo}

A emancipação literária da mulher perpassa a consciência do seu próprio corpo como material poético. A imagem que perdurou da mulher - a idealizada, a cortejada, a inacessível, detentora de uma imagem imaculada, ou a implacável - constitui um postulado que fomentou a sua desvalorização secular fora do espaço doméstico.

Durante o Romantismo, as mulheres surgem como seres idealizados, fragilizados, portadores de grande beleza, envoltos em misticismo. A figura feminina é descrita através do recurso a qualidades demoníacas, capazes de seduzir e destronar os homens que com elas cruzam o seu caminho. Tais representações devem-se essencialmente aos escritos de autoria masculina, numa tentativa de relegar o elemento feminino para um segundo plano, subjugando-o às tarefas domésticas e, deste modo, perpetuando a rigidez do poder patriarcal.

Nos séculos XIX e XX, a mulher vai emergindo na esfera social, libertando única exclusivamente do espaço doméstico. A sua projeção, porém, não foi tão evidente como a do homem; a sua voz não tinha nem a mesma intensidade nem o mesmo impacto da voz masculina. E foi precisamente por este motivo que elegemos as três escritoras, dado que as obras poéticas de Judith Teixeira (1888-1959); Florbela Espanca (1894 - 1930) e Maria Teresa Horta (1937 -) sinalizam um percurso de experimentação da representação do corpo, da sensualidade e do erotismo femininos secularmente interdito.

Virginia Woolf no brilhante e icônico ensaio intitulado $A$ room of one's own, cuja tradução em português é, Um teto todo seu, assevera a necessidade de a mulher ter independência, ter o seu papel e lugar de criação. Para Woolf, "uma mulher precisa de dinheiro e um teto todo seu, um espaço próprio, se quiser escrever ficção" (WOOLF, 2014, p. 15). Na concepção da escritora, a independência financeira e espaço adequado à intimidade traduz a possibilidade de um pleno desenvolvimento artístico, instâncias de difícil acesso à mulher em séculos anteriores e ainda não plenamente conquistadas. Assim, a consciência dessa falta material e espacial que, na visão de Woolf, poderia ter dado às mulheres uma participação mais efetiva no meio artístico, pode ser alargada a ní- 
vel temático e físico, uma vez que a disposição do seu próprio corpo como material literário foi interditada, proibida, diminuída. Todas que tencionaram adentrar nessa seara, em maior ou menor grau, pagaram o preço de tal gesto. São disso exemplo Judith Teixeira e Florbela Espanca, cuja obra e percursos biográficos foram ardilosamente deturpados. Também Maria Teresa Horta foi violentamente atacada por ousar escrever poesia erótica num período em que a mulher assumia o papel de dona de casa, tendo sido severamente alertada que tal punição servia para lhe interditar a escrita.

As três autoras, apesar de viverem em épocas distintas, coincidem em escutar o ruído de uma crítica literária machista, tradicionalista e redutora, que não reconhece o valor poético dos seus versos, mas o desvio moral que, na sua visão distorcida, se desprendia dos poemas das suas autorias.

Portanto, ao estabelecer uma espécie de condição favorável à criação artística, Virgínia Woolf também estava denunciando a falta de um contexto que permitisse às mulheres a capacidade de desenvolver a sua Arte. Com base neste postulado e, recuperando o título do ensaio Woolfiano, Um teto todo seu, acrescentamos que as mulheres precisaram também de "um corpo todo seu", para que pudessem ser sujeitos que fruíssem das mesmas possibilidades sociais e criativas dos homens. Deste modo, consciência do corpo concorre para a emancipação da mulher, na medida em que é essa autocencialização que Ihe permite explorá-lo, trabalhá-lo no texto e transgredi(r)-lo.

\section{Um corpo poético e erótico}

Judith Teixeira, Florbela Espanca e Maria Teresa Horta foram mulheres percursoras e também prevaricadoras. Anna Klobucka reporta a este fato em O Formato Mulher: a Emergência da Autoria Feminina na Poesia Portuguesa, sublinhando o "posicionamento epistemologicamente secundário do "feminino" em relação ao "masculino" na tradição ocidental e a desigualdade, simbólica e material, entre os homens e as mulheres" (KLOBUCKA, 2009, p. 67). Na verdade, a mulher era "privada do poder simbólico da autoria e da autoridade cultural" (KLOBUCKA, 2009, p. 70), o que teve, como já assinalado, consequências pesarosas nas suas vidas. 
As três escritoras, Teixeira, Espanca e Horta, recuperam no texto o corpo, enquanto material poético e erótico, força metonimizadora capaz de sintetizar desejos, pulsações, possibilidades de tantos amores... mas, ao trilharem esse espaço, sofreram o revés violento da tentativa de interdição: Judith Teixeira passou mais de 50 anos quase que totalmente esquecida por leitores e estudiosos da literatura. As temáticas que afloram nos teus textos desencadearam uma forte animosidade. Por exemplo, o semanário humorístico lisboeta Sempre fixe divulgou uma caricatura da autora, onde esta surge disforme, gorda, sob o título Viande de paraître e uma recriação parodística do poema "A bailarina vermelha", denominado "A bailarina côr de sangue" que rebaixa a autora - "Ela pena / Entornando suor / A desfazer-se em banha" (TEIXEIRA, 1996, s/p. ). Teixeira não foi reconhecida como "mulher nem como artista", atacada por "publicar porcarias sexuais trescalando ao môrno fatum d'alcova." (Revolução Nacional, 1926, p. 04). Já Florbela Espanca, por questões que perpassam seu suicídio e sua biografia, teve, depois de morta, que responder a um longo processo disciplinar, sendo mais conhecida por sua vida pregressa (tornada pelo Salazarismo como espécie de exemplo a não ser tomado) do que pela sua obra. E ainda em vida, a artista alentejana, segundo relata Maria Lúcia Dal Farra (1996, p. IX- XXVI) conheceu o sectarismo de uma crítica literária bastante redutora e machista, que lia os seus versos como uma blasfêmia. Maria Teresa Horta, tempos depois, a despeito de viver em uma época mais "avançada", viu o seu livro Minha Senhora de Mim ser apreendido pela Polícia Política portuguesa e ainda sofreu perseguições e ataques.

Estes episódios persecutórios perpassam o ideário de que essas mulheres ousaram falar de algo específico, algo que se sabe, que se diz, que se explora (em muitas conotações). Paradoxalmente, a dona do corpo e do discurso parece não poder usufruir em sua inteireza do corpo feminino.

Não causava espécie, por exemplo, que mulheres escrevessem (apesar do diminuto número em séculos anteriores), mas que não ultrapassassem o "bom senso moral". Assim, abundavam nos escritos femininos assuntos ligados às prendas domésticas, amores idealizados, apego à família e à maternidade... aquilo que foi convencionalmente chamado de temas do "caderno rosa". Nessa convenção, não cabiam os temas do universo do erotismo 
e, sobretudo, de um corpo que deseja e tem o afã (e até realiza!) as suas vontades. Nessa perspectiva, o paradigma medieval que admitia Maria como exemplo e Eva como antimodelo do feminino deitou raízes nos séculos posteriores: aquela sempre retrata vestida da cabeça aos pés, dogmamente sempre virgem, sempre superior à mulher quase nua e expulsa do Paraíso, por desobediência. Nessa esteira, Eva representa a perdição e Maria a reparação, pois gerou Jesus, o Salvador para o Cristianismo. Eva convenceu Adão a comer do fruto proibido, Maria, mesmo virgem, concebeu a Redenção - eis, portanto, o imaginário sexual subjacente a isso tudo: a incapacidade de ser alguém "moralmente decente" quando se adentra a um campo onde o corpo feminino é explorado pela própria mulher - a sempre virgindade de Maria lhe tira o que lhe é mais feminino para lhe adensar o patamar da santidade. Via contrária, a demonização de Eva perpassa a crença de que "o fruto proibido" seria uma metáfora para as questões ligados ao sexo.

À luz da lógica medieval, Teixeira, Espanca e Horta aproximam-se de Eva e distanciam-se de Maria, justamente por ousarem ter um "corpo todo seu", pois é através da consciência que detêm do próprio corpo que podem conhecê-lo, explorá-lo no texto e transgredi(r)-lo. Tal como Eva, também elas foram expulsas do paradigma atribuído à mulher do seu tempo porque ousaram escrever e inscrever-se no texto, percorrendo temas e semas que lavram sobre o desejo e o corpo interditos.

O corpo em Teixeira assume uma feição marcadamente erótica, dilacera todas as convenções e molesta a mentalidade de um país cerzido por imposições morais e pela rigidez de valores. A autora granjeou comentários austeros, sendo sempre associada à perversão. Referimo-nos muito particularmente aos poemas que integram Decadência, nomeadamente "A minha colcha encarnada" (TEIXEIRA, 2015, p. 81), no qual o eu lírico assume de forma explícita o seu frémito, o seu êxtase e arrebatamento. Se em 1922, data da publicação do poema, o desejo era um tema interdito, Judith não só versa sobre ele como o celebra; exalta o corpo e canta explicitamente o prazer, numa ascensão orgástica, plenamente assumida e descrita por um sujeito feminino que descreve com deleite a sua embriaguez: "Em espasmos delirantes, / numa posse insaciada - / "rasgo as sedas provocantes (...) Tomo o cetim às mãos cheias... / Sinto latejar 
as veias / na minha carne abrasada! / Torcem-me o corpo desejos... / mordendo o cetim com beijos / numa ânsia desgrenhada!" (TEIXEIRA, 2015, p. 81). Também o poema "A minha amante" (TEIXEIRA, 2015, p. 82) patenteia, para além da irreverência extrema, devassidão. Além da eroticidade que percorre todo o poema, há um elemento inusitado e polémico anunciado pelo título. "A minha amante" parece aflorar a relação homoerótica mantida com a amante. Assim, a despeito de todo o preconceito e no caso em tela de dupla ordem (feminino e homoerótico), o sujeito lírico parece não se importar com quem refrata o que se passa na intimidade de duas mulheres que se desejam. Não escapa a Teixeira o entorno de maledicência que isso poderia causar, ao início do século XX e mesmo assim, essa hora má é consubstanciada na hora linda. Por outro lado, se condicionarmos a leitura ao intento da epígrafe ("a dor só lhe perco o som e a cor em orgias de morfina") a dita "tara perversa" pode ser perfeitamente lida como a ideia do uso recreativo da morfina e ela ser a própria "amante" do eu lírico e, para além dessa ambiguidade engendrada no poema, resta clara a disposição de entregar o próprio corpo feminino ao espectro de prazeres proibidos - a um amor homoerótico, simbolizado aqui por outra mulher ou à droga, morfina que, naquela altura, estava em voga nos meio artísticos e intelectuais" (SEVERINO, 2017, p. 238). A alegria daqui resultante desmantela todo um tecido moral imaginado para o que seria o papel da mulher.

Nessa mesma linha, o poema "Educação Sentimental" de Maria Teresa Horta permite refletir sobre os papéis pensados socialmente para as mulheres. Este poema abre o livro de 1975, que tem o mesmo nome e, de cara, implode a noção de ser a mulher o polo sempre passivo de uma relação sentimental. A ideia difundida pelos trovadores de cantar vassálico, uma dama inatingível, idealizada (mote muito aproveitado tanto por Maria Teresa Horta como por Florbela Espanca, para subvertê-lo) cristalizou-se no imaginário literário. Horta, sem negar um diálogo com a própria Tradição Literária, inverte essa lógica masculinizada e falocêntrica e traz à tona um corpo feminino consciente de suas zonas erógenas, tão consciente que através do tato ensina o próprio corpo a alguém que o tem de aprender: 


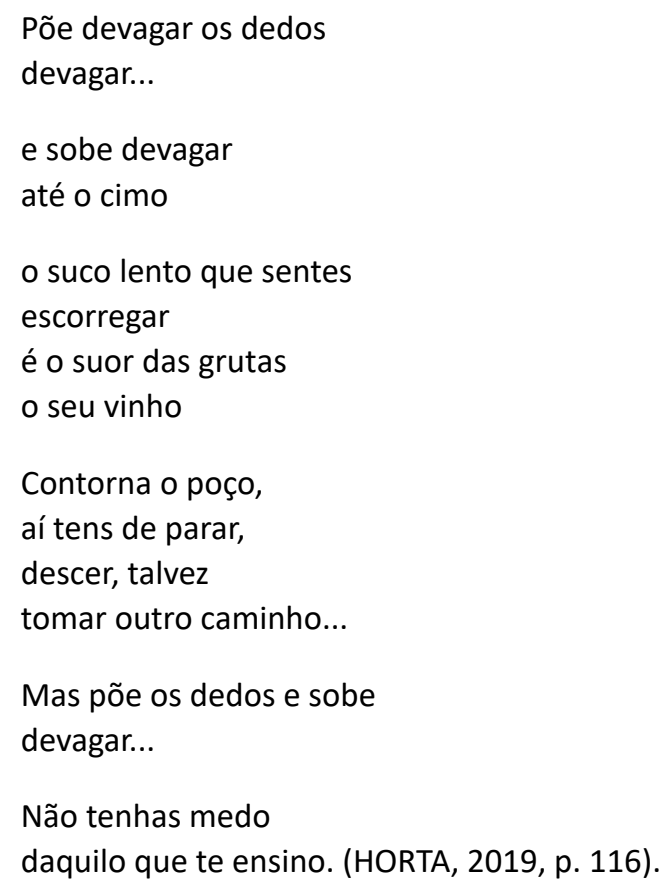

Partindo do pressuposto de que só se ensina o que se sabe e saber-se sujeito de seu próprio corpo, ser dona de si é, no mínimo, é uma resposta a tempos e tempos de negação à plenitude do corpo que se tem. A ideia de um didatismo, resgatada no título que é o mesmo do livro de Flaubert, de 1869, também soa como diálogo e ruptura, resposta à formação masculina preconizada pelo autor francês e femininamente construída no livro de Horta.

Na mesma esteira, o soneto "Toledo", de Florbela Espanca, pertencente ao livro Charneca em Flor (o volume poético flagrantemente mais erótico e sensual da poetisa alentejana) encampa a comunhão de dois corpos prestes a se entregarem ao prazer sexual, num ritual sinestésico e solar:

Diluído numa taça de oiro a arder Toledo é um rubi. E hoje é nosso! O sol a rir... Vivalma... Não esboço Um gesto que me não sinta esvaecer...

As tuas mãos tacteiam-me a tremer... Meu corppo de âmbar, harmonioso e moço, É como um jasmineiro em alvoroço Ébrio de sol, de aroma, de prazer! 
Cerro um pouco o olhar, onde subsiste

Um romântico apelo vago e mudo

- Um grande amor é sempre grave e triste.

Flameja ao longe o esmalte azul do Tejo...

Uma torre ergue ao céu um grito agudo...

Tua boca desfolha-me num beijo...

(ESPANCA, 1996, p. 227).

Chama atenção o forte apelo erótico que é metonimizado pela torre - elemento que aponta para a semântica fálica -, e que conduz ao céu o grito agudo, deixando-se, assim, a entrever a dinâmica da conjunção carnal. Dessa maneira, o ato sexual é retrato como um rito de excitação prévia onde o corpo feminino "harmonioso e moço", que se perfumou e se ornou de jasmim, é o motivo do frêmito das mãos que lhe tateiam, para depois ir lhe desfolhar. Assim, as imagens apontam para a comunhão sexual e podem revelar, sem que sejam excluídos outros sentidos próprios, um eu lírico bastante cônscio dos seus desejos e atributos sexuais, desmantelando a lógica machista que sempre atribuiu ao corpo feminino um lugar de interdição, quase inumano de tantas vedações às ânsias, vontades e volúpias no feminino.

\section{Volúpias}

Teixeira, Espanca e Horta irromperam num espaço interdito e fizeram-no com consciência e audácia. Escrever constitui uma forma de se protegerem da solidão e inclusive da estranheza que causa a sua escrita. Escrever implica refletir, distanciar-se e é esse distanciamento em que se colocam que lhes permite uma análise mais concreta. $\mathrm{O}$ ato de escrita possibilita a expressão de um eu que se revela e prolonga na combustão do desejo, como sucede, em Volúpia.

Não é despiciendo que, sob o mesmo título, mas com diferentes tônicas, nuances e intensidades, as três autoras componham os seus poemas. $O$ título apela à leitura, quer pelo incômodo que poderia aportar na época perpassada por interdições e imposições de decoro, quer pelo prazer nele anunciado. Volúpia reporta à deusa romana do prazer, Voluptas, nascida da união entre Cupido e Psiqué, dotada de poder de persuasão e luxúria. 0 
lexema remete ainda para o prazer decorrente dos sentidos; para o aprazimento intelectual, moral e estético; para a preponderante propensão para o prazer dos sentidos, nomeadamente os prazeres eróticos e ainda para a qualidade do que proporciona sugere ou inspira prazer erótico. Ora, as acepções da palavra confluem e demarcam a temática das diferentes composições de Volúpia o deleite intelectual e estético que decorre do exercício escrito, mas que concomitantemente fere a moral vigente nos contextos em que foram escritos, sobretudo porque era negado o deleite ao elemento feminino.

Assim, o poema "Volúpia" de Judith Teixeira revela, na primeira quadra, o eu poético confessadamente exangue, com "braços trémulos e cansados" mas ainda receptivo aos beijos que recebia: "Era já tarde e tu conOtinuavas / entre os meus braços trémulos, cansados... / E eu, sonolenta, já de olhos fechados, / bebia ainda os beijos que me davas!" (TEIXEIRA, 2015, p. 146). Os versos decassílabos de rima interpolada marcam a cadência e acentuam o passar das horas e a densidade do que nelas se desenrola: "Passaram horas!... Nossas bocas flavas, / Muito unidas, em haustos repousados, / Queimavam os meus sonhos macerados, / Como rescaldos de candentes lavas" (TEIXEIRA, 2015, p. 146). Apesar das horas transcorridas, as bocas permanecem incandescentes, anunciada pelo adjetivo "flavas", cor de ouro ou trigo maduro", bem como pela forma verbal "queimavam" e expressão imagética de pendor hiperbolizante "rescaldos candentes de lavas". O beijo, a união das bocas flavas, a alcova, os rúbidos adejos criam, como assinala Inês Pedrosa, "uma intensa metonímica dos corpos em combustão" (PEDROSA, 2017, p. 221):

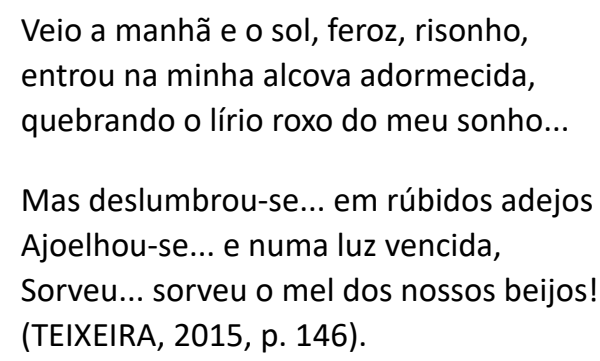

Teixeira revela um criterioso labor na seleção da palavra. Os semas por ela utilizados bem como a respetiva disposição sequencial contribuem para recriar um clima de intimidade incan- 
descente. Se os adejos são movimentos de asa para deslocação e sustentação do corpo, neste contexto, parecem representar a intensidade e movimentação corpo em busca do prazer, criando imagens transgressoras, em combinações ousadas, às quais "acrescenta tópicos e o vocabulário do decadentismo finissecular" (PEDROSA, 2017, p. 221) como são o exemplo de sono, a noite e a sensualidade recriada pela intensidade das cores, evidenciando um eu rendido ao desejo e ao amor.

Por sua vez, o poema "Volúpia" de Florbela Espanca inicia-se com a exaltação da juventude "divino impudor da mocidade" que se anuncia como uma época divina pelas potencialidades que encerra; a seiva e o vigor, inerente à mocidade, permite-lhe dar-se num completo arrebatamento, entregando o "corpo prometido à morte": "No divino impudor da mocidade, / Nesse êxtase pagão que vence a sorte, / Num frémito vibrante de ansiedade, / Dou-te o meu corpo prometido à morte!" (ESPANCA, 1996, p. 238). O corpo trasmuda-se em cálice sagrado "Meu corpo! Trago nele um vinho forte:" (ESPANCA, 1996, p. 238). Assim, o vinho, símbolo da bebida de vida pode estar ainda associado ao sacrifício, anunciada pela devoção total ao outro no último verso da primeira quadra "Dou-te o meu corpo prometido à morte". O sonete prossegue: "A sombra entre a mentira e a verdade... / A nuvem que arrastou o vento norte... / --- Meu corpo! Trago nele um vinho forte: / Meus beijos de volúpia e de maldade! (ESPANCA, 1996, p. 238). Contrariamente ao sujeito poético de "Volúpia" de Teixeira, este eu lírico assume-se mais ativo e inclusive audaz. Não se limita a receber beijos ou estar abraçado. É mais transgressor dá beijos de volúpia e maldade. Também o seu peito são flores vermeIhas e os dedos são sol quando abraçam, mas certeiros como lanças que se cravam no peito:

Trago dálias vermelhas no regaço...

São os dedos do sol quando te abraço,

Cravados no teu peito como lanças!

E do meu corpo os leves arabescos

Vão-te envolvendo em círculos dantescos

Felinamente, em voluptuosas danças...

(ESPANCA, 1996, p. 238). 
O poema anuncia um festim de sentidos, táteis, visuais, gustativos, que contribuem para o acentuar das capacidades sedutoras do eu lírico que tateia e envolve de forma implacável, mas envolta em arrebatadora sensualidade, o objeto de desejo. A sugestão dionisíaca confere um tom pagão e fortemente sexual ao poema. Há uma espécie de consciência do pecado, afinal, os beijos são de "volúpia e de maldade", adensados por metáforas que vão construindo uma atmosfera afrodisíaca e sedutora. Nesse diapasão, seduzir alguém é, em última análise, um ato de autoconhecimento e o eu lírico florbeliano sabe dos predicados do seu corpo, da capacidade sedutora encerrada nele, na dança que atrai e envolve o interlocutor. Tudo sugestiona uma espécie de malícia, um canto de sereia sabedor do que pode fazer e conseguir. Assim, num contexto onde o apelo ao corpo feminino é para dessexualizá-lo, a consciência da potência corporal feminina surge como insurreição literária a isso tudo. Assim, é o sujeito lírico feminino o polo ativo da conquista, da sedução, da ação, modus operandi impensável para a convenção trovadoresca, por exemplo.

Contrariamente ao que sucede com os poemas anteriores, assistimos em "Volúpia" de Maria Teresa Horta a um eu lírico conhecedor do seu corpo, como patenteiam o uso de imperativos "Retém; entorna; corre; desce; troca e deixa" que funcionam como pedidos, ou instruções que o sujeito poético faculta ao parceiro para que ele percorra os passos que conduzem ao prazer:

\author{
Retém em mim o olhar \\ entorna a boca no poço \\ Corre os lábios \\ nos meus ombros \\ desce a vertigem no dorso \\ Troca a penumbra \\ das pernas \\ pelo luar do meu gosto \\ Deixa os dedos encontrarem \\ a penumbra do pescoço \\ (HORTA, 2006, p. 66).
}


O destaque dado ao corpo assume assaz importância, funciona como uma espécie de cartografia: território de encontro, de fusão, da união entre imanência e transcendência, mas é a tônica que confere ao corpo masculino, enquanto objeto de desejo que se destaca a sua poesia. Horta distancia-se da delicada melancolia de Teixeira e do papel de implacável sedutora do poema florbeliano, delinenando um sujeito conhecedor do seu corpo, o que the permite facultar diretrizes na senda do prazer. Existe uma galeria de poema hortianos que celebram o corpo, o prazer físico individual ou partilhado. A mulher é a protagonista na descoberta detalhada do pulsar, do ritmo e das sensações do corpo-seu. Assistimos ao desejo imperativo para que a boca se entorne no "poço" os lábios avancem pelo dorso, as pernas sejam preteridas ao local/luar onde brilha o gosto e os dedos percorram o pescoço. Como refere Maria Teresa Horta: "Eu escrevo com as palavras do corpo, sou uma muIher da sensualidade. Vejo isso através da minha escrita. Para mim, tudo tem corpo" (HORTA, 2012). O erotismo é o corpo da poesia. Assim, Maria Teresa escreve com as palavras do corpo, e as palavras permitem-lhe inscrever o corpo no corpo do texto.

\section{Conclusão}

O exercício aqui empreendido pretende constituir uma reflexão de como o corpo feminino se transmutou em material poético e, consequentemente, numa via simbólica de transgressão num contexto adverso à condição de mulher e de escritora.

Efetivamente, a poética destas mulheres assenta, em certa medida, na consciência do seu corpo, um corpo que inverte as regras instituídas; que se insurge e revela, que grita e que irrompe no texto com uma força inusual, expressando um desejo incomum, dado que era silenciado.

As três escritoras parecem preconizar o pensamento de Hélène Cixous (1995) que defende que a mulher deve assumir-se como veículo transmissor da sua própria voz, sendo o sujeito dos seus enunciados. Cixous considera que a mulher deve fazer com que o corpo seja escutado, de forma a rebater o discurso do poder, isto é, o discurso masculino imposto durante séculos. Na sua ótica, a escrita e o corpo assumem funções equiparáveis, sobretudo quando se faz referência a um corpo e a uma escrita femininos. 
Neste sentido, Judith Teixeira, Florbela Espanca e Maria Teresa Horta coincidem no facto de evocarem o corpo feminino, de o trabalharem e explorarem de modo refletirem e expressarem a sua liberdade desejante. Por isso, o corpo feminino se transmutou em matéria literária capaz de transpor as imposições das convencionalidades que recaíam sobre o papel da mulher na sociedade. Em última análise, através deste corpo literário, puderam simbolicamente experienciar as amplas possibilidades eróticas e erógenas que qualquer corpo humano detém. $E$, assim, pela literatura, conseguiram criar um mundo à parte, no qual sexo, amor e desejo também fossem naturalmente acessados pela mulher, num exercício de escolha ou de livre consentimento. Não obstante, pagaram o preço e sentiram a voracidade da sociedade e da Crítica, que não aceitaram as transgressões.

\section{Referências}

CIXOUS, H. La risa de la medusa: Ensayos sobre la escritura. (Trad. Ana María Moix y Myriam Díaz-Diocaretz). Barcelona: Editorial Anthropos, 1995.

DAL FARRA, M. L. O affaire Florbela Espanca. In: ESPANCA, Florbela. Poemas. São Paulo: Martins Fontes, 1996, p. IX- XXVI.

ESPANCA, F. Poemas. São Paulo: Martins Fontes, 1996.

HORTA, M. T. Inquietude. Lisboa: Quasi Edições, 2006.

HORTA, M. T. A poeisia erótica de Maria Teresa Horta. In: Revista Máxima. 12 de setembro, disponível em: https://www.maxima.pt/celebridades/detalhe/ maria-teresa-horta-a-colecionadora-de-palavras. Acesso em 22 fev. 2021.

KLOBUCKA, A. O Formato Mulher: a Emergência da Autoria Feminina na Poesia Portuguesa. Coimbra: Angelus Novus, 2009.

PEDROSA, I. Judith Teixeira e Maria Teresa Horta: poéticas do corpo. In: SILVA Fabio Mario; RITA, Annabela; DAL FARRA, Maria Lúcia (Orgs). Judtih Teixeira e ensaios críticos: no centenário do Modernismo. Lisboa: Edições Esgotadas, 2017, pp 215-226.

Revista Revolução Nacional. Casa D’Orates: doida sim e porque sim. 2 de julho, 1926, p. 4. 
SEVERINO, I. Judith Teixeira e Florbela Espanca: revisitadas In: SILVA, F. M.; RITA, A.; DAL FARRA, M. L. (Orgs). Judtih Teixeira e ensaios críticos: no centenário do Modernismo. Lisboa: Edições Esgotadas, 2017, p. 237-245.

TEIXEIRA, J. Poemas. Lisboa: \&etc, 1996.

TEIXEIRA J. Poesia e Prosa. Organização e estudo introdutório de Fabio Mário da Silva e Cláudia Pazos Alonso. Lisboa: Dom Quixote, 2015.

WOOLF, V. Um teto todo seu. São Paulo: Tordesilhas, 2014. 